\title{
Experimental Study on the Combustion Properties of an Alcohol-to-Jet Fuel
}

\author{
Sandra Richter, Clemens Naumann, Uwe Riedel \\ German Aerospace Center (DLR), Institute of Combustion Technology \\ Pfaffenwaldring 38-40, 70569 Stuttgart, Germany \\ sandra.richter@dlr.de
}

\begin{abstract}
Alcohol-to-Jet - Synthetic Paraffinic Kerosene (AtJ-SPK) is an alternative fuel made from biotechnologically produced isobutanol and recently approved for the use as biofuel in aviation for blending with conventional jet fuel up to an amount of $30 \%$. In contrast to the multicomponent crude oil Jet A-1, AtJ-SPK consists mainly of two highly branched components. Thus, it is of fundamental interest to look at the characteristic combustion behavior and to assess differences compared to Jet A-1 if there are any. Therefore two global combustion properties - laminar burning velocity and ignition delay time - were investigated experimentally for AtJSPK as well as for Jet A-1. The results for both fuel types are similar. However, less reactivity for AtJ-SPK can be deduced from the experiments, a behavior which can be linked to its structure.
\end{abstract}

Keywords: Alcohol-to-Jet, synthetic paraffinic kerosene, biofuel, Jet A-1, laminar burning velocity, ignition delay time

\section{Introduction}

Up to now fuels used for transportation are predominantly made from crude oil. Compared to these classical fuels biofuels have several advantages, among those the most important are ensuring security of supply, sustainability, and due to their carbon life cycle the overall reduction of carbon dioxide emissions [1,2]. The raw materials used for biofuel production can be classified into four types of biomass according to their molecular structure and material properties as there are sugar, starch, lignocellulose and vegetable oils. Whereas sugar, starch and vegetable oils are gained from cultivation farming, residues from agriculture and forestry are the sources for lignocellulose. Regarding the competition to traditional agriculturally produced food and forage as well as an intelligent sustainability the lignocellulose material should be kept in mind as the most promising feedstock. Details about actual developments and process technologies for biofuel production can be found in the literature, see e.g. [3-6].

Usually, three kinds of fuels are discerned: gasoline, diesel and jet fuel. The fuel type is independent of the source, the differences in the composition and physical properties are adjusted during the production process, which applies to the production of crude oil based fuels as well as to alternative fuels. But a big difference lies in the approval of these fuels which is easier to achieve for gasoline or diesel than for jet fuels like Jet A-1, because it is mostly used in civil aviation all over the world and over a wide range of ambient conditions. The major aspects are safety reasons, while physical and chemical properties of Jet A-1 have to meet standard specifications like ASTM D1655. To ensure the compatibility of alternative fuels with conventional Jet A-1 these fuels have to comply with the standard ASTM D7566, and by this specification, a new fuel can be used as drop-in-fuel, i.e. blending crude oil Jet A-1, up to a certain amount depending on the approval.

Recently approved as drop-in fuel is Alcohol-to-Jet - Synthetic Paraffinic Kerosene (AtJ-SPK) [7], an iso-paraffinic jet fuel made from alcohols by (I) dehydration, (II) oligomerisation, and (III) hydrogenation [4-6, 8]. Besides AtJ-SPK there is another AtJ fuel called AtJ-SKA (Synthesized Kerosene with Aromatics) [8] which has not been approved yet; therefore, in this study we are focusing on AtJ-SPK. All alcohols in a molecular size range from $\mathrm{C}_{2}$ to $\mathrm{C}_{5}$ are possible raw materials [8], but only the production process using isobutanol is certificated according to ASTM D7566 [7] and can be used as $30 \%$ blend. Since alcohol can be produced by chemical synthesis as well as in a biotechnological process it is important to note that only AtJ made from biomass-based alcohol can be considered a biofuel. The ethanol production by fermentation of sugar or starch is well known. Meanwhile, through some genetic manipulations in the microorganisms also 
isobutanol is made via this process. Fermentation of lignocellulosic material or gasfermentation are further process developments [5, 8], e.g. the U.S. biotechnology company Gevo had produced the first cellulosic AtJ which was used in a commercial flight [8]. The investigated AtJ-SPK fuel was also produced by Gevo and contains two main components: 2,2,4,6,6-pentamethylheptane $\left(\mathrm{C}_{12} \mathrm{H}_{26}, w=88 \%\right)$ and 2,2,4,4,6,8,8-heptamethylnonane $\left(\mathrm{C}_{16} \mathrm{H}_{34}, w=12 \%\right)$ [8]. Both structures are shown in Fig. 1. For this study, experiments were performed on this AtJ-SPK and on Jet A-1, for comparing the results with a conventional fuel, by measuring the characteristic combustion properties laminar burning velocity and ignition delay time, each at different pressures and equivalence ratios.<smiles>CCCCCC(C)CC(C)(C)C</smiles><smiles>CC(CC(C)(C)C)CC(C)(C)CC(C)(C)C</smiles>

Fig. 1: Chemical structure of both components of the Alcohol-to-Jet fuel AtJ-SPK investigated in this study.

\section{Laminar Burning Velocity}

The measurements of the laminar burning velocity for premixed AtJ-air flames were carried out at a preheattemperature of $473 \mathrm{~K}$, pressures of $0.1,0.3$ and $0.6 \mathrm{MPa}$ and at a wide range of the equivalence ratio $\varphi$. The cone angle method used and the burner system have already been described in previous studies on alternative fuels [10-13].

\subsection{Experiment}

A schematic of the experimental setup is presented in Fig. 2; it consists of three main parts: the preparation of the fuelair mixture, the burner itself with the nozzle, and the detection and evaluation system. For the preparation of the fuel-air mixture first the fuel (in this study AtJ-SPK and Jet A-1, respectively) was vaporized at temperatures between $590 \mathrm{~K}$ and $660 \mathrm{~K}$ and mixed with preheated nitrogen (purity $99.999 \%$, Linde). The temperature of the fuel- $\mathrm{N}_{2}$ mixture was proximately reduced to the set-temperature of $473 \mathrm{~K}$. In a second homogenizing step the oxygen (purity $99.95 \%$, Linde) was added to mimic the ratio in air $\left(\mathrm{N}_{2}: \mathrm{O}_{2}=79: 21\right)$. In the case of the liquid fuels, the flow rates of the fluids were controlled by an HPLC-pump (LC-20AD, Shimadzu), and for $\mathrm{N}_{2}$ and $\mathrm{O}_{2}$ by mass flow controllers (F-111B, Bronkhorst), respectively. Premixed conical-shaped flames were stabilized above the flame holder using a coflow, which was necessary to enable measurements for a wide $\varphi$-range. As coflow gases air was used for rich and a mixture of $5 \% \mathrm{CH}_{4}, 5 \% \mathrm{H}_{2}$ and $90 \% \mathrm{~N}_{2}$ for lean flames with an overlap around stoichiometric conditions. All measurements at elevated pressures as well as the measurements of lean mixtures at atmospheric pressure have been performed within a burner housing, providing a heat exchanger unit and a throttle valve.

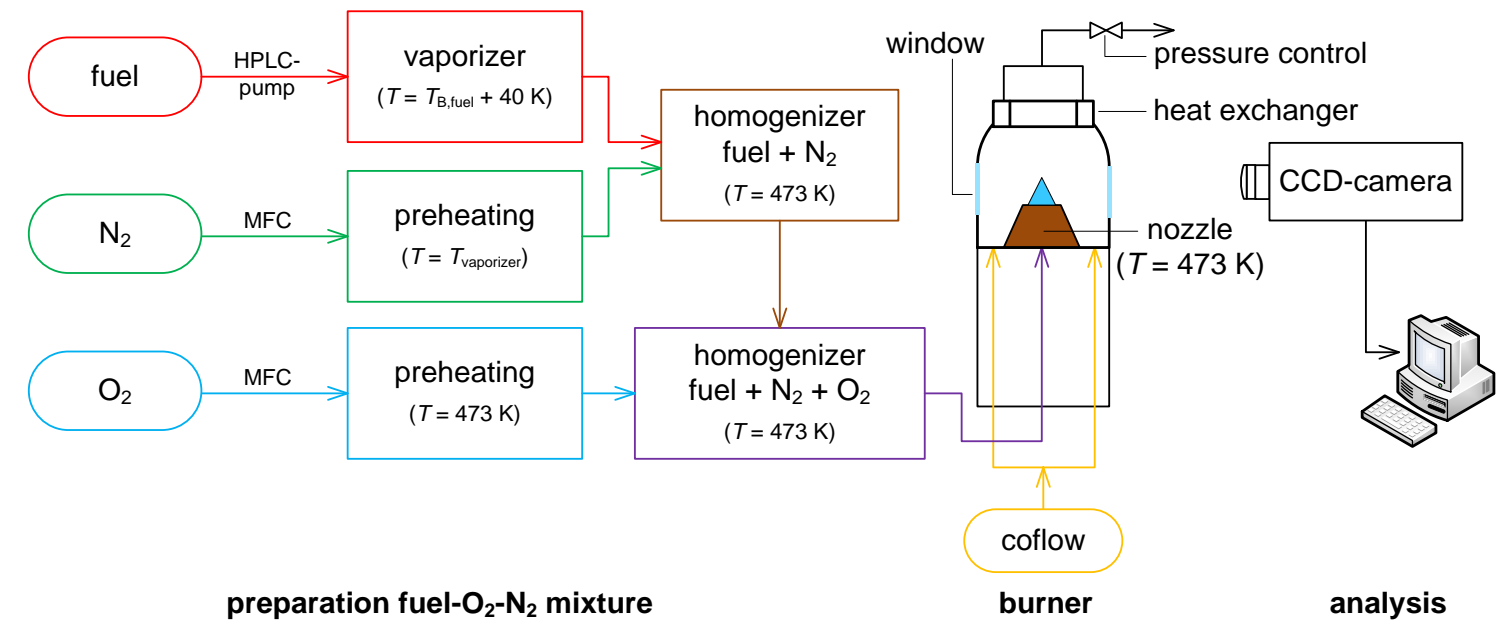

Fig. 2: Experimental setup of the burner system for measuring the laminar burning velocity using the cone angle method $\left(T_{\mathrm{B}}-\right.$ boiling temperature, MFC - mass flow controller). 
For the evaluation pictures of the flames were recorded with a CCD-camera (Imager Intense, LaVision) and used to determine the cone angle. According to Eq. 1 and Fig. 3 the laminar burning velocity $S_{\mathrm{u}}$ was calculated from the angle $\alpha$ and the velocity of the unburned gas $v_{\mathrm{u}}$.

$$
S_{\mathrm{u}}=v_{\mathrm{u}} \cdot \sin \alpha
$$

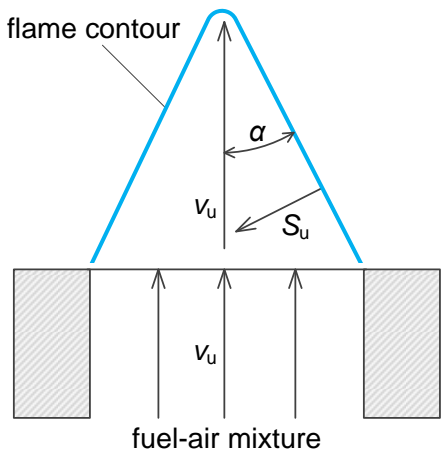

Fig. 3: Determination of the laminar burning velocity $S_{\mathrm{u}}\left(v_{\mathrm{u}}\right.$-flow speed of the unburned gas mixture, $\alpha$-cone angle).

\subsection{Results}

Figure 4 shows the experimental results for the laminar burning velocity of the AtJ fuel investigated and the data of Jet A-1 for comparison. At $p=0.1 \mathrm{MPa}$ the measurements were performed in an $\varphi$-range from 0.6 to 2.0 , the limits of flame stabilization. At elevated pressures this range was slightly smaller. The laminar burning velocity decreases with increasing pressure and all curves have their maximum near the stoichiometric region. In detail the maxima are located at $\varphi=$ 1.05 at $S_{\mathrm{u}}=78.4 \mathrm{~cm} / \mathrm{s}$ for $p=0.1 \mathrm{MPa}$ and for $0.3 \mathrm{MPa}$ and $0.6 \mathrm{MPa}$ at $\varphi=1.10$ with $S_{\mathrm{u}}=71 \mathrm{~cm} / \mathrm{s}$ and $S_{\mathrm{u}}=58 \mathrm{~cm} / \mathrm{s}$, respectively. With increasing and decreasing equivalence ratio the differences between the different pressures become smaller or vanish nearly completely within the range of experimental uncertainties (see Fig. 4 for the errors derived from the experimental measurements). The uncertainties, resulting from the accuracies of the mass flow controllers, the cone angle detection and the treatment of the fuel as ideal gas, were estimated to be in the range of $2 \%$ at stoichiometric conditions increasing to $13 \%$ at the outmost equivalence ratios and rise with increasing pressure.

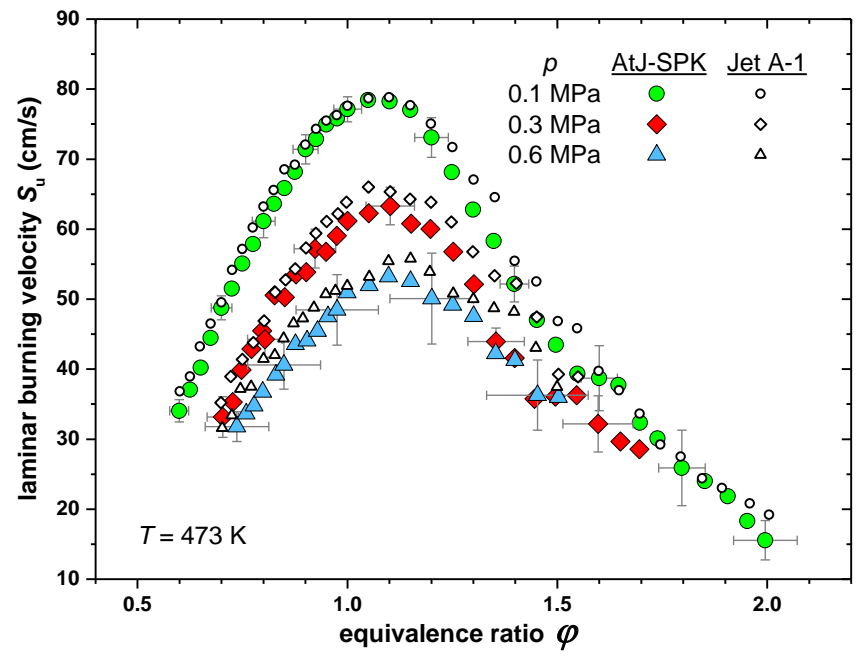

Fig. 4: Experimental results for the laminar burning velocity for Alcohol-to-Jet - Synthetic Paraffinic Kerosene (AtJ-SPK) and Jet A-1.

The comparison to Jet A-1 shows that the laminar burning velocity measured for the biofuel AtJ-SPK is similar to the one for the conventional jet fuel. A slight trend to lower values for AtJ is visible compared to Jet A-1.That may be an effect 
from the structure of the AtJ-SPK fuel which consists mainly of two highly branched iso-alkanes (see Fig. 1) whereas Jet A-1 is a multicomponent mixture, which contains iso-alkanes with different grades of branching, but also linear (without branching) and cyclic alkanes and aromatics. It is a general observation, that highly branched alkanes are less reactive than slightly branched or linear alkanes and this behaviour is also reflected by the laminar burning velocity. Also Won et al. [13] had found similar laminar flame speeds for AtJ from Gevo and a conventional fuel as well as for other alternative fuels; moreover they remark a lower reactivity for this AtJ fuel.

\section{Ignition Delay Time}

The measurements of the ignition delay time were performed at different conditions for AtJ-SPK and Jet A-1. The experiments were carried out in a high pressure shock tube for two different equivalence ratios $(\varphi=1.0$ and 2.0$)$, and by varying the initial temperature between $800 \mathrm{~K}$ and $1700 \mathrm{~K}$. The initial pressure was chosen to about $p_{\text {init }}=1.6 \mathrm{MPa}$. All fuelair mixtures were diluted with nitrogen so that the resulting mixture was composed of $50 \%$ fuel + synthetic air and $50 \%$ nitrogen, defined as dilution 1:2. A detailed description of the experiment was given in previous studies, see e.g. [12, 13].

\subsection{Experiment}

The principle setup of the shock tube with gas supply, fuel-air- $\mathrm{N}_{2}$ mixture preparation, and the position of the measuring instruments is shown in Fig. 5. At first the driver section, heated to $120^{\circ} \mathrm{C}$, was filled with helium (He) and argon (Ar) using two mass flow controllers (F-232M, Bronkhorst). Here, helium was used as the main component whereas argon was added to match the acoustic impedance of the driver gas. These tailored conditions allow longer measurement times [15]. The driven section was heated to temperatures between $160^{\circ} \mathrm{C}$ and $180{ }^{\circ} \mathrm{C}$ and pumped down to pressures below $0.01 \mathrm{~Pa}$ by a turbomolecular pump. Fuel-air- $\mathrm{N}_{2}$ mixtures were prepared manometrically in a 5 liter heated storage vessel and evacuated using a separate turbomolecular pump. For each experiment a new mixture was prepared by injecting the fuel with a syringe onto fibres permanently purged by hot nitrogen (purity $99.999 \%$, Linde) and transported into the evacuated vessel, followed by the addition of preheated synthetic air (80 vol- $\% \mathrm{~N}_{2}, 20 \mathrm{vol}-\% \mathrm{O}_{2}$, purity $99.9995 \%$, Linde). After a mixing time of 10 min the fuel-air- $\mathrm{N}_{2}$ mixture was filled into the shock tube. The optimal mixing period, gas preheat temperatures, and the composition of the mixture have been determined and controlled by gas chromatographic analysis monitoring fuel degradation and recovery rate.

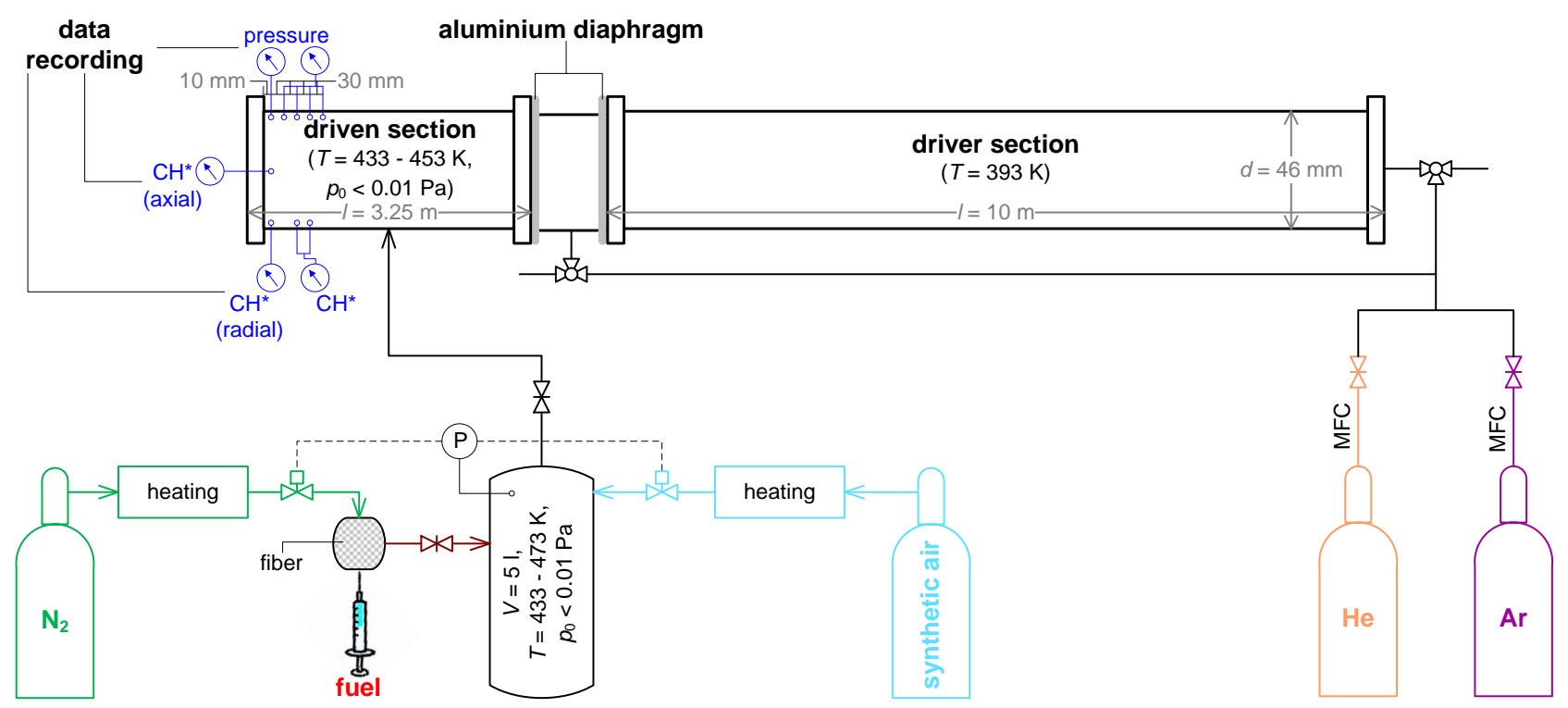

Fig. 5: Schematic of the used shock tube showing fuel-air- $\mathrm{N}_{2}$ mixture preparation, gas supply, and position of the measuring instruments $\left(\mathrm{CH}^{*}\right.$ - activated $\mathrm{CH}$-radicals; $d$-diameter, $l$ - length, $V$ - volume, $p_{0}$ - pressure of the evacuated system, MFC - mass flow controller). 
The ignition was observed by measuring the pressure profiles with piezo-electric gauges (PCB 112A22 and Kistler 603B coated with a thin layer of RTV106), located at a distance of $1 \mathrm{~cm}$ from the end flange, and also by the detection of the the $\mathrm{CH}^{*}$-emission at $431 \mathrm{~nm}$ at the same position and through the end flange as well. The wavelength of the $\mathrm{CH}^{*}$ emission was selected by a narrow band pass filter (Hugo Anders, FWHM $=5 \mathrm{~nm}$ ) and measured with a photomultiplier (Hamatsu R3896) in combination with a logarithmic amplifier (Femto HLVA-100). In addition, two measurement ports at a distance of $7 \mathrm{~cm}$ and $10 \mathrm{~cm}$ from the end flange were detecting the $\mathrm{CH}^{*}$-chemiluminescence emitted by the deflagration wave. All ignition delay time values were determined by measuring the time difference between the initiation of the system by the reflected shock wave and the occurrence of the maximum of the $\mathrm{CH}^{*}$-signal at the measurement port located at a distance of $1 \mathrm{~cm}$ from the end flange (see Fig. 6 as exemplification for this definition). Only ignition delay times below $40 \mu \mathrm{s}$ at the highest temperatures were evaluated from the end plate emission peak, which defines ignition delay time more exactly neglecting any propagation effects due to deflagration. The initial temperature and pressure behind the reflected shock wave were computed from the incident shock speed, measured with four piezo-electric pressure gauges at intervals of $30 \mathrm{~mm}$ using a one-dimensional shock model. The estimated uncertainty in the initial reflected shock temperature is less than $\pm 15 \mathrm{~K}$ throughout the temperature range of our measurements. Nevertheless, especially for longer ignition delay time measurements, post-shock compression due to attenuation of the reflected shock wave as shown in Fig. 6 slightly increases pressure and temperature of the mixture before heat release starts to take effect. This has to be taken into account when modelling the data.

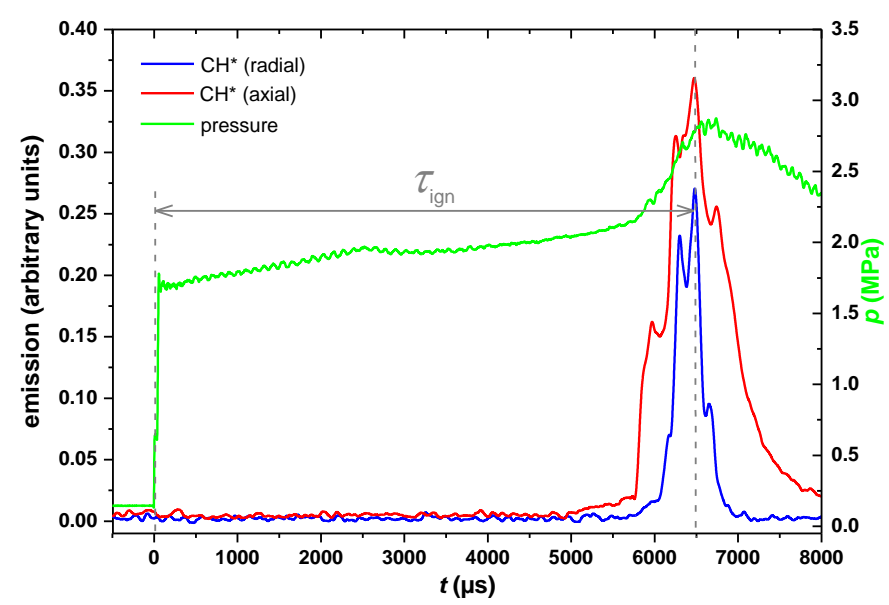

Fig. 6: Definition of ignition delay time $\tau_{\mathrm{ign}}$ on the basis of typical $\mathrm{CH}^{*}$-emissions and pressure profile.

\subsection{Results}

In Fig. 7 the results for the measurements of the ignition delay time for the biofuel AtJ-SPK are shown and compared to the conventional fuel Jet A-1. Looking at first to the values for the AtJ fuel at $\varphi=1.0$ and $\varphi=2.0$ it can be asserted that the stoichiometric and rich mixtures of AtJ-SPK with synthetic air have nearly the same behaviour regarding the ignition delay time. Differences between the different $\varphi$-values appear by comparing to Jet A-1: At $\varphi=1.0$ the ignition delay time for Jet A-1 at low temperatures is slightly longer than for AtJ-SPK. Between $1000 \mathrm{~K}$ and $1200 \mathrm{~K}$ the ignition delay times of both fuels are similar, whereas for $T>1250 \mathrm{~K}$ the ignition delay time for Jet A-1 becomes noticeably shorter with increasing temperature. In contrary, at $\varphi=2.0$ the ignition delay for Jet A-1 is at high as well as at low temperatures shorter than for AtJ-SPK except in the range between $1100 \mathrm{~K}<T<1250 \mathrm{~K}$, where they are within the same range. Moreover, in the low temperature regime Jet A-1 ignition delay times tend to become shorter with decreasing temperature compared to $\varphi$ $=1.0$ and to AtJ-SPK as well. The longer ignition delay times for AtJ-SPK at $T>1250 \mathrm{~K}$ indicate that it is less reactive than Jet A-1.

A comparison of measured ignition delay times for AtJ-SPK with other jet fuels was already presented by Zhu et al. [16] and Valco et al. [17] who have performed their experiments also in a high pressure shock tube [16] and in a rapid compression machine [17] respectively. In those studies it is also shown that AtJ-SPK has longer ignition delay times than conventional jet fuels and hence it has been concluded that AtJ-SPK has a lower reactivity resulting from the highly branched structure. Zhu et al. [16], who measured the ignition delay time at initial pressures of 3 and 6 atm, respectively, 
have shown that the differences between AtJ-SPK and other fuels decrease with increasing pressure. This finding is confirmed by our work as we have also found small differences up to identical results.

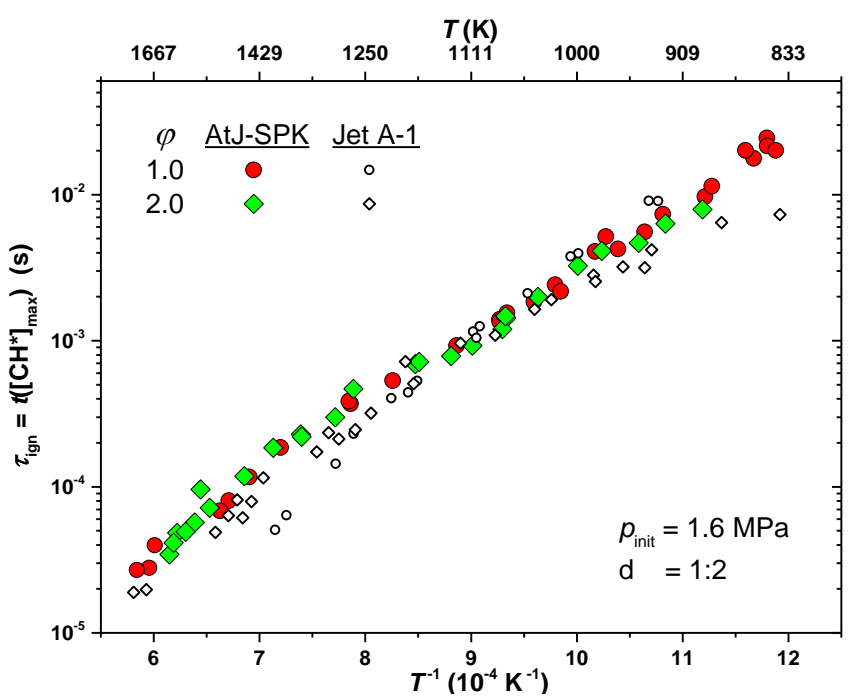

Fig. 7: Experimental results of the ignition delay time $\tau_{\text {ign }}$ for Alcohol-to-Jet - Synthetic Paraffinic Kerosene (AtJ-SPK) and Jet A-1 $\left(p_{\text {init }}-\right.$ initial pressure, $\mathrm{d}$ - dilution).

\section{Conclusion}

In this study two characteristic combustion properties - laminar burning velocity and ignition delay time - of the biofuel AtJ-SPK, being suitable as alternative aviation fuel, were experimentally investigated and compared to the conventional aviation fuel Jet A-1. The results for the laminar burning velocity show predominantly smaller values for AtJ-SPK indicating a lower reactivity especially with increasing pressure. The same conclusion can be made from the measurements of the ignition delay time since the ignition delay of AtJ-SPK is predominantly longer (especially at $T>1250 \mathrm{~K}$ ) than of Jet A-1. Solely at low temperatures $(T<1100 \mathrm{~K})$ and $\varphi=1.0 \mathrm{Jet}$ A-1 has a slightly longer ignition delay time, whereas for $\varphi=2.0$ a transition to an NTC (Negative Temperature Coefficient) regime might be possible. A less reactivity of AtJ-SPK comparing to a conventional jet fuel is also reported in the literature $[14,16,17]$ and can be explained by his highly branched structure.

\section{Acknowledgements}

The authors thank S. Scheuermann and J. Ortner from the Bundeswehr Research Institute for Materials, Fuels and Lubricants (WIWeB, Erding, Germany) for suppling us with Alcohol-to-Jet (SPK). Furthermore we thank M. B. Raida for her support measuring the laminar burning velocity and N. Ackermann, Ph. Coens and $\mathrm{H}$. Dreyer for their experimental support measuring the ignition delay times. A part of the measurements on Jet A-1 was performed within the EU-tender SWAFEA under service contract No. Tren/F2/408.2008/SI2.518403/SI2.519012.

\section{References}

[1] M. Braun-Unkhoff and U. Riedel, “Alternative fuels in aviation,” CEAS Aeronaut. J., vol. 6, no. 1, pp. 83-93, 2015.

[2] L. Rye, S. Blakey and C. W. Wilson, "Sustainability of supply or the planet: a review of potential drop-in alternative aviation fuels," Energy Environ. Sci., vol. 3, no. 1, pp. 17-27, 2010.

[3] V. K. Gupta and M. G. Tuohy (Editors). Biofuel Technologies, Berlin, Heidelberg: Springer-Verlag, 2013.

[4] W.-C. Wang and L. Tao, "Bio-jet fuel conversion technologies," Renew. Sust. Energ. Rev., vol. 53, pp. 801-822, 2016.

[5] U. Neuling and M. Kaltschmitt, "Conversion routes for production of biokerosene - status and assessment," Biomass Conv. Bioref., vol. 5, no. 4, pp. 367-385, 2015.

[6] R. Mawhood, E. Gazis, S. de Jong, R. Hoefnagels, R. Slade, "Production pathways for renewable jet fuel: a review of commercialization status and future prospects," Biofuels, Bioprod. Bioref., vol. 10, no. 4, pp. 462-484, 2016. 
[7] Federal Aviation Administration (FAA). (2016, April 22). New Alternative Jet Fuel Approved [Online]. Available: https://www.faa.gov/news/updates/?newsId=85425 (accessed: 2016, November 15)

[8] A. Zschocke, S. Scheuermann and J. Ortner. High Biofuel Blends in Aviation (HBBA) [Online]. Available: http://www.hbba.eu/

[9] Gevo. (2016, November 14). Alaska Airlines to Fly Today on Gevo's Cellulosic Renewable Alcohol-to-Jet Fuel [Online]. Available: http://ir.gevo.com/phoenix.zhtml?c=238618\&p=irol-newsArticle \&ID=2222130

[10] Th. Kick, T. Kathrotia, M. Braun-Unkhoff, U. Riedel, "An experimental and modeling study of laminar flame speeds of alternative aviation fuels," in Proceedings of GT2011, ASME Turbo Expo, Vancouver, Canada, 2011, GT2011-45606.

[11] Th. Kick, J. Herbst, T. Kathrotia, J. Marquetand, M. Braun-Unkhoff, C. Naumann, U. Riedel, “An Experimental and Modeling Study of Burning Velocities of Possible Future Synthetic Jet Fuels," Energy, vol. 43, no. 1, pp. 111-123, 2012.

[12] A. Mzé-Ahmed, P. Dagaut, K. Hadj-Ali, G. Dayma, Th. Kick, J. Herbst, T. Kathrotia, M. Braun-Unkhoff, J. Herzler, C. Naumann, U. Riedel, "Oxidation of a Coal-to-Liquid Synthetic Jet Fuel: Experimental and Chemical Kinetic Modeling Study," Energy Fuels, vol. 26, no. 10, pp. 6070-6079, 2012.

[13] P. Dagaut, F. Karsenty, G. Dayma, P. Diévart, K. Hadj-Ali, A. Mzé-Ahmed, M. Braun-Unkhoff, J. Herzler, T. Kathrotia, Th. Kick, C. Naumann, U. Riedel, L. Thomas, "Experimental and Detailed Kinetic Model for the Oxidation of a Gas to Liquid (GtL) Jet Fuel," Comb. Flame, vol. 161, no. 3, pp. 835-847, 2014.

[14] S. H. Won, P. S. Veloo, S. Dooley, J. Santner, F. M. Haas, Y. Ju, F. L. Dryer, "Predicting the global combustion behaviors of petroleum-derived and alternative jet fuels by simple fuel property measurements," Fuel, vol. 168, pp. 34-46, 2016.

[15] J. Herzler, L. Jerig, P. Roth, "Shock tube study of the ignition of lean n-heptane/air mixtures at intermediate temperatures and high pressures," Proc. Comb. Inst., vol. 30, no. 1, pp. 1147-1153, 2005.

[16] Y. Zhu, S. Li, D. F. Davidson and R. K. Hanson, "Ignition delay times of conventional and alternative fuels behind reflected shock waves," Proc. Comb. Inst., vol. 35, no. 1, pp. 241-248, 2015.

[17] D. J. Valco, K. Min, A. Oldani, T. Edwards, T. Lee, "Low temperature autoignition of conventional jet fuels and surrogate jet fuels with targeted properties in a rapid compression machine," Proc. Comb. Inst., 2016, http://dx.doi.org/10.1016/j.proci.2016.05.032. 